\title{
The influence of time management skills on stress and academic performance level among nursing students
}

\author{
Sitah Alshutwi, Haya Alkhanfari, Norah Sweedan \\ College of Nursing, King Saud bin Abdul-Aziz University for Health Sciences, Saudi Arabia
}

Received: January 29, 2018

DOI: $10.5430 /$ jnep.v10n1p96
Accepted: April 21, 2019

Online Published: October 10, 2019

\begin{abstract}
College students need to possess many skills to successfully pass each year of study. Effective time management skills are an essential characteristic for college students to have in order to maintain good academic performance. The students' ability to manage their time properly is linked to many positive consequences, such as higher academic performance and lower stress levels. Despite the importance of time management skills for students, a limited number of studies were conducted to examine this issue among students in Saudi Arabia, especially nursing students. Therefore, the aim of this study was to explore the influence of time management skills on stress and academic performance levels of nursing students in Saudi Arabia. In this quantitative research, a cross-sectional design was used to explore the relationship between the level of time management skills and stress level of nursing students. A total of 150 students completed a survey (a response rate of 65\%). The two scales included in this survey were the Student Nurse Stress Index and Time Management Questionnaire. Pearson's correlation coefficient showed that there was a positive and significant correlation between the time management skills and academic performance of the students. That is, the increasing level of time management skills was associated with increasing academic performance $(r=.240, p<.003)$, there was a positive and significant correlation between the time management skills and year of study $(r=.262, p<.001)$, and there was a positive and significant correlation between the stress level and year of study $(r=.249, p<.002)$. Therefore, time management and stress management training programs should be provided for nursing students during the orientation period.
\end{abstract}

Key Words: Nursing students, Time management, Academic performance, Stress level

\section{INTRODUCTION}

Time is an important resource everyone possesses equally, yet individuals may fail to utilize the time properly as they lack of some skills for time management. In academic life, empirical evidence revealed that academic achievement was associated with effective time management. ${ }^{[1]}$ Being a college students can be a stressful experience for many nursing students. Heavy clinical and academic workloads and many assignments and deadlines can be overwhelming for students. The effective time-management skills are essential characteristics for nursing students to improve their aca- demic performance and achievements. ${ }^{[2]}$ Time management for students was defined as "clusters of behavioural skills that are important in the organization of study and course load.". ${ }^{[3]}$ These behavioural skills may include the ability for goals setting, priorities tasks, and using mechanism of time management and being organized and oriented about using time. ${ }^{[4,5]}$ Guided by the theory of time management, ${ }^{[6]}$ students need to find the optimal way to use their time to successes on their study.

In the literature, students' ability to management their

*Correspondence: Sitah Alshutwi, PhD, Assistant professor; Email: shutwis@ksau-hs.edu.sa; Address: College of Nursing, King Saud Bin Abdul-Aziz University for Health Sciences, Saudi Arabia. 
time properly was linked with many positive consequences. For example, a research conducted by Karim and Kandy (2011) ${ }^{[7]}$ revealed that the positive impact of time management skills on self-efficacy was detected. Consistently, a study conducted by Karim (2015) ${ }^{[8]}$ found that the training of time management skills has a positive influence on students' self-efficacy. Students who acquired time management skills were more likely to report high self-efficacy. ${ }^{[8]}$

A well-documented research showed a positive association between time management skills and academic performance among students. ${ }^{[7]}$ An interventional study conducted by Karim and Kandy (2011) ${ }^{[7]}$ revealed that those students who received time management training session showed improved academic performance and higher achievement compared with those who did not received any training to improve their time management skills. Despite the evidence on the positive influence of time management in students' academic performance, few studies revealed that there was not significant correlation. For example, Swart et al. (2010) ${ }^{[9]}$ explored the relationship between time management skills and the academic achievement of African engineering students and concluded that there was no statistically significant relationship between time management skills and the academic achievement of African engineering students. Yet, some researchers argued that the time management skills could predict students' academic performance. ${ }^{[10]}$

More factors have shown positive association with improved time-management skills such as stress level. A study conducted in United Arab Emirates showed that there was a significant relationship between time management, stress reduction and increased academic achievement. ${ }^{[11]}$ Similarly, older studies found consistent result where the time management was negatively associated with perceived stress; individuals with higher level of time management skills perceived stress to be lower and managed. ${ }^{[12]}$ Specific stress related to academic performance (perceived academic stress) and achievement was also found to have a negative association with time management behaviors among students. ${ }^{[13]}$

Despite the importance of time management skills for students there are limited studies were conducted among students in Saudi Arabia, specially nursing students. Therefore, the aim of this study was to explore the influence of time management skills on the stress and academic performance levels among nursing students in Saudi Arabia. Furthermore, the levels of time management skills, stress, and academic performance were compared among different level nursing students.

Published by Sciedu Press

\section{METHOD}

\subsection{Design and procedure}

In this quantitative research, a cross-sectional design was used to explore the relationship between the levels of time management skills and stress among nursing students. This study was conducted in the College of Nursing of King Saud bin Abdul-Aziz University for Health Sciences, Riyadh. The data were collected from nursing students during their professional phase, which includes year three (Levels 5 and 6) and year four (Levels 7 and 8).

\subsection{Sample}

Sample size calculation software (Raosoft; Raosoft Inc., Seattle, WA, USA) was used to determine the sample size for this study. Convenience sampling was used and pen-and-paper self-report questionnaires were employed to gather the data. The questionnaires were distributed among all nursing students in Levels 5, 6, 7, and 8 at the current study's site. Using the total population of 230 nursing students who were enrolled at the site, a confidence interval of $95 \%$, and an alpha of .05, the recommended target sample size was 145 nursing students. A total of 150 students completed the surveys (a response rate of $65 \%$ ).

\subsection{Measurement tools}

For this study, two scales with a total of 46 items and demographic questions were used. The time required to complete the survey was estimated to be 15-20 minutes. The two scales included in this survey were the Student Nurse Stress Index and Time Management Questionnaire.

\subsection{Ethical considerations}

The research team, which included the principal investigator and co-investigators, maintained the confidentiality and privacy of all of the information obtained from the participants. The data were also kept confidential, and only the research team had access to the surveys.

\subsection{Statistical analysis}

All data were entered and analyzed using IBM SPSS Statistics for Windows version 20 (IBM Corp., Armonk, NY, USA). Descriptive statistics were used to describe and summarize the sample characteristics, which included the mean, standard deviation, frequencies, frequency distributions, and percentages. Pearson's correlation coefficient $(r)$ was used to assess the strength and direction of the associations between the variables. The p-value was used to evaluate the significance of the correlation; p-value of .05 was accepted as significant. 


\section{Results}

\subsection{Descriptive statistics}

The final sample included 150 nursing students, with 40 students from Level 5, 37 students from Level 6, 41 students from Level 7, and 32 students from Level 8 . One hundred and twenty-nine students were between 21 and 25 years old and 21 students were less than 20 years old. The majority of the students were single $(\mathrm{n}=135), 13$ students were married, and three had children. The mean grade point average (GPA) was 3.00. There was no major variation in the distribution of the students in terms of the level of study (see Table 1).

Table 1. Students level distribution

\begin{tabular}{lll}
\hline Students' level & Frequency & Valid Percent \\
\hline Level 5 (year 3) & 40 & 26.7 \\
Level 6 (year 3) & 37 & 24.7 \\
Level 7 (year 4) & 41 & 27.3 \\
Level 8 (year 4) & 32 & 21.3 \\
TOTAL & 150 & 100.0 \\
\hline
\end{tabular}

The Pearson's correlation coefficient showed that there was a positive and significant correlation between the time management skills and academic performance of the students Those who were able to manage their time were progressing well in their academic performance, as indicated by their GPA $(r=.240, p<.003)$. Furthermore, there was a positive and significant correlation between the time management skills and year of study $(r=.262, p<.001)$, with senior students being more able to manage their time than junior students. No significate correlation was found between the demographic variables (age, marital status, and number of children) and stress.

Regarding the time management skills, the results of this study showed that most students $(62 \%)$ wrote down a set of priorities for each day. In addition, most of them (53.3\%) noted important dates (exam dates, research paper due dates, etc.) on a single calendar, whereas $28.7 \%$ of them never wrote down a set of goals for each day, and some of them $(58 \%)$ found themselves waiting around a lot without anything to do. Most of the students $(60.7 \%)$ kept items with them that they could work on whenever they had a spare moment.

For the stress, the results showed that some students (26\%) were extremely stressed when they had a lack of free time or feared failing the course. Similarly, 25.3\% were extremely stressed when they had too much responsibility, and 32\% were fairly stressed when they did not have enough time for their family. There were some students who did not feel stressed about some situations, such as personal and health problems (18.7\%), the physical health of other family 98 members (23.3\%), and relationships with parents (24.7\%). Overall, students reported being stressed in all categories of the stress index; that is, academic load, clinical concerns, interface worries, and personal problems (see Table 2).

Table 2. Aspect of stress

\begin{tabular}{lll}
\hline Aspect of Stress & Low & High \\
\hline Academic load & $6 \%(9 / 150)$ & $94 \%(141 / 150)$ \\
Clinical concerns & $18.7 \%(28 / 150)$ & $81.3 \%(122 / 150)$ \\
Interface worries & $2.7 \%(4 / 150)$ & $96.7 \%(145 / 150)$ \\
Personal problem & $26.7 \%(40 / 150)$ & $73.3 \%(110 / 150)$ \\
\hline
\end{tabular}

The stress level was negatively correlated with the level of time management $(r=-.227, p<.001$; see Table 3$)$. Students who had limited time management skills were more stressed than those who were managing their time properly. Specifically, stress from academic load and clinical concerns was significantly correlated with the time management skills. Students with a lower level of time management skills were highly stressed from the academic load $(r=-.19, p<.05)$ and clinical concerns $(r=-.237, p<.01$; see Table 3$)$.

\section{Discussion}

The primary objective of this study was to evaluate the influence of time management skills on the stress and academic performance levels of nursing students in Saudi Arabia. Time management is a vital skill that helps people to be more productive and organized. Good time management is necessary for everybody, especially for university students whose calendar is often filled with activities and classes. The findings of this study showed that good time management skills were associated with high levels of academic achievement. This result is comparable with that of Nasrullah and Khan $(2015)^{[4]}$ who found that the impact of time management on the students' academic achievements indicated that successful students are good time managers. The finding of this study is also aligned with that of Eldeeb and Eldosoky $(2016)^{[14]}$ who reported that the majority of nursing students have low levels of time management. However, the result contradicts that of Alkhatib's (2014) ${ }^{[15]}$ study of time management among college students in the United Arab Emirates, which found that the students generally had a moderate level of time management.

Academic stress among nursing students is caused by excessive workloads or other responsibilities. The results of this study showed that when the students were in a higher year of study, their stress level increased. However, this finding is not congruent with the results of Eldeeb and Eldosoky $(2016)^{[14]}$ who found that Level 3 students had higher mean stress scores than Level 8 students.

ISSN 1925-4040 E-ISSN 1925-4059 
Table 3. Aspect of stress and time management correlations

\begin{tabular}{|c|c|c|c|c|c|c|c|}
\hline & & TIME & $\begin{array}{l}\text { Personal } \\
\text { Problem }\end{array}$ & $\begin{array}{l}\text { Academic } \\
\text { load }\end{array}$ & $\begin{array}{l}\text { Clinical } \\
\text { concerns }\end{array}$ & $\begin{array}{l}\text { Interface } \\
\text { worries }\end{array}$ & Stress \\
\hline TIME & Pearson Correlation & 1 & & & & & \\
\hline Management & Sig. (2-tailed) & & & & & & \\
\hline \multirow{2}{*}{$\begin{array}{l}\text { Personal } \\
\text { Problem }\end{array}$} & Pearson Correlation & $-.182 *$ & 1 & & & & \\
\hline & Sig. (2-tailed) & .025 & & & & & \\
\hline \multirow{2}{*}{$\begin{array}{l}\text { Academic } \\
\text { load }\end{array}$} & Pearson Correlation & $-.193 *$ & $.449 * *$ & 1 & & & \\
\hline & Sig. (2-tailed) & .018 & .000 & & & & \\
\hline \multirow{2}{*}{$\begin{array}{l}\text { Clinical } \\
\text { concerns }\end{array}$} & Pearson Correlation & $-.237 * *$ & $.529 * *$ & $.679 * *$ & 1 & & \\
\hline & Sig. (2-tailed) & .004 & .000 & .000 & & & \\
\hline \multirow{2}{*}{$\begin{array}{l}\text { Interface } \\
\text { Worries }\end{array}$} & Pearson Correlation & -.237 & $.425^{* *}$ & $.639 * *$ & $.571 * *$ & 1 & \\
\hline & Sig. (2-tailed) & .110 & .000 & .000 & .000 & & \\
\hline \multirow{2}{*}{ Stress } & Pearson Correlation & $-.227 * *$ & $.726 * *$ & $.839 * *$ & $.845^{* *}$ & $.829 * *$ & 1 \\
\hline & Sig. (2-tailed) & .007 & .000 & .000 & .000 & .000 & \\
\hline
\end{tabular}

**Correlation is significant at the 0.01 level (2tailed).

In the current study, as the year of study increased, the prevalence of stress increased among the nursing students. This may weaken their learning skills, which could affect the quality of patient care that they provide after graduation. There was also a considerable negative association between the stress level and the students' academic performance, which indicates that when the level of stress increases, academic performance decreases.

\section{Conclusion}

The results of this study add to the body of knowledge regarding students' stress, time management, and academic achievement. There was a statistically significant positive correlation between the effectiveness of the students' time management, stress levels, and GPA. Therefore, a time management preparation program and stress management training programs should be provided for nursing students during the orientation period. Furthermore, giving the students time to study outside of the class or at home would have a positive effect on their studies whereas spending more time working has some negative impacts on the students' output. Faculty need to consider the academic load and other courses assignments as they can have a negative effect on students and they can increase their stress level, especially among those who lack time management skills.

There are a few limitations of this study that restrict the generalizability of the findings. First, the study relied on self-report measures and the students were even asked to report the GPA. No objective measures were used in this study. Second, there was a limited sample size; thus, replications of this study are needed that include larger samples from different nursing schools. Third, no male students were included in this study. Including males in future studies could reveal the impact of gender on the level of time management and stress.

\section{CONFlicts of InTERest Disclosure}

The authors declare that there is no conflict of interest.

\section{REFERENCES}

[1] McKenzie K, Gow K. Exploring the first year academic achievement of school leavers and mature-age students through structural equation modelling. Learning and Individual Differences. 2004; 14(2): 107-123. https://doi.org/10.1016/j.lindif.2003.10.002

[2] Tsai HB, Liu S. Relationships between time-management skills, Facebook interpersonal skills and academic achievement among junior high school students. Social Psychology Of Education. 2015; 18(3): 503-516. https : //doi .org/10.1007/s11218-015-9297-7

[3] Sansgiry SS, Bhosle M, Sail K. Factors that affect academic performance among pharmacy students. The American Journal of Pharma- ceutical Education. 2006. PMid:17149433 https ://doi .org/10 $.5688 / \mathrm{aj} 7005104$

[4] Nasrullah S, Khan MS. The Impact of Time Management on the Students' Academic Achievements. Journal of Literature, Languages and Linguistics. 2015; 2422-8435.

[5] Kaushar PM. Study of Impact of Time Management on Academic Performance. IOSR Journal of Business and Management. 2013; 59-60. https ://doi .org/10.9790/487X-0965960

[6] Koch CJ, Kleinmannn M. A stitch in time saves nine. Behavioral decision making explanations for time management problems. Eu- 
ropean. Journal of Work \& Organizational Psychology. 2002; 11: 199-217. https ://doi.org/10.1080/13594320244000120

[7] Karim S, Kandy M. Time Management Skills Impact on Self-Efficacy and Academic Performance. Journal of American Science. 2011; 7: 720-726.

[8] Karim S, Kandy M. Time management skills impact on self-efficacy and academic performance. Journal of American Science. 2015; $7(12)$.

[9] Swart AJ, Lombard K, Jager H. Exploring the relationship between time management skills and the academic achievement of African engineering students - a case study. European Journal of Engineering Education. 2010; 35(1): 79-89. https://doi.org/10.1080/03 043790903480316

[10] Tanriogen A, Iscan S. Time management skills of PamukkaleUniversity students and their effects on academic achievement. Eurasian Journal of Educational Research. 2009; 35: 93-108.
[11] Al Katib AS. Time Managmement and Its Relation To Students' Stress, Gender and Academic Achivement Among Sample of Students at Al Ain University of Sience and Technology, UAE. International Journal of Business and Social Research. 2014.

[12] Macan TM, Shahani C, Dipboye RL, Phillips AP. College students' time management: Correlations with academic per-formance and stress. Journal of Educational Psychology. 1990; 82: 760-768. https://doi.org/10.1037/0022-0663.82.4.760

[13] Misra R, McKean M. College Students' Academic Stress and Its Relation to Their Anxiety, Time Management, and Leisure Satisfaction. American Journal of Health Studies. 2000; 16: 41-51.

[14] Eldeeb GA, Eldosoky EK. Relationship between Effectiveness of Time Management and Stress levels among Nursing Students. Journal of Nursing and Health Science. 2016; 5(2): 95-100.

[15] Al Khatib AS. Time Management and Its Relation to Students' Stress, Gender and Academic Achievement among Sample of Students at Al Ain University of Science and Technology, UAE. International Journal of Business and Social Research (IJBSR). 2014; 4: 47-58. 